\title{
Summer Drought Assessment Based on Vegetation Supply Water Index in Chongqing
}

\author{
Shiqi Yang, Yanghua Gao \\ Chongqing institute of meteorological sciences \\ Chongqing, China \\ yangshiqi@gmail.com
}

\author{
Yongjin $\mathrm{Xu}$ \\ School of Geographical Sciences \\ Southwest University \\ Chongqing, China \\ xuyj@swu.edu.cn
}

\begin{abstract}
This paper choose MODIS product data of single-day and 8d synthesis from June to September in 2006 to construct vegetation supply water index (VSWI) for Chongqing summer drought condition, and validated results by soil moisture; while the correlation between VSWI and precipitation is discussed, and spatial and temporal distribution of drought in Chongqing were gotten using 8d synthetic data. The results showed that: (1) $V S W I_{E}$ built by EVI was more suitable for monitoring summer drought in Chongqing than $V S W I_{N}$ built by NDVI, and VSWI built by single-day MODIS data has better correlation than VSWI built by 8-day synthetic MODIS data; (2) VSWI had a certain negative correlation with precipitation; (3) VSWI could effectively reflect the spatial and temporal differences in soil moisture, and it was an effective mean to assess summer drought.
\end{abstract}

Keywords- Vegetation supply water index (VSWI); summer drought; Chongqing

\section{INTRODUCTION}

Drought is the water shortage by water budget or supply and demand imbalance. Because of high frequency, wide range and long duration, drought has become the world's major natural disasters. According to Obasi's statistics [1], approximately $85 \%$ of natural disasters are related to extreme meteorological events, and the losses caused by drought has accounted for more than half.

Soil condition is one of important indicators to evaluate drought. Relative to the traditional monitoring methods, remote sensing methods can get surface information widely and timely. Extensive research on remote sensing for drought monitoring has been carried out, and a lot of methods have been established to assessment the surface moisture status [26]. Relative to the Landsat-TM and NOAA-AVHRR, Terra/Aqua-MODIS have high time resolution, high spectrum resolution, and moderate spatial resolution, which can get soil information timely and has advantage in drought monitoring [7].

There are regional and periodic droughts in Chongqing because of the complex terrain and uneven precipitation distribution. In this paper, MODIS data of different Temporal Resolution (single-day and 8d synthesis) and different vegetation index (Normalized Difference Vegetation Index, NDVI and Enhanced Vegetation Index, EVI) are to construct vegetation supply water index (VSWI) in Chongqing, and the results are compared by soil moisture. Meanwhile, the temporal evolution of the 2006 severe drought is analyzed by
VSWI, and the relationship between VSWI and precipitation is discussed, and spatial and temporal distribution of drought in Chongqing were gotten using $8 \mathrm{~d}$ synthetic data.

\section{DATA AND METHOD}

\section{A. Remote sensing Data and Pre-processing}

The MODIS products can be gotten from the NASA EOS Data Gateway in the United States. In Chongqing, the time of July-August is high incidence season for drought. Considering cross-season droughts and soil moisture data, we selected monitoring period from June to September in 2006. (Generally, the summer drought means drought happened in June, July and August. To express conveniently in this article, summer drought means drought occurred in June-September).Remote sensing data with different time resolution MODIS data products in June-September of 2006 (vegetation index for 2000-2009) are shown in table I . The products have been processed for atmospheric correction and geometric correction, and can be used by projection transformation, mosaic and cutting only [8].

TABLE I. MODIS PRODUCTS

\begin{tabular}{|c|c|c|c|}
\hline Code & Content & $\begin{array}{c}\text { Spatial } \\
\text { Resolution }\end{array}$ & $\begin{array}{c}\text { Temporal } \\
\text { Resolution }\end{array}$ \\
\hline M0D09GA & albedo & $500 \mathrm{~m}$ & $1 \mathrm{~d}$ \\
\hline M0D09A1 & albedo & $500 \mathrm{~m}$ & $8 \mathrm{~d}$ \\
\hline M0D11A1 & $\begin{array}{c}\text { surface } \\
\text { temperature }\end{array}$ & $1 \mathrm{~km}$ & $1 \mathrm{~d}$ \\
\hline M0D11A2 & $\begin{array}{c}\text { surface } \\
\text { temperature }\end{array}$ & $1 \mathrm{~km}$ & $8 \mathrm{~d}$ \\
\hline M0D11C3 & $\begin{array}{c}\text { surface } \\
\text { temperature }\end{array}$ & $1 \mathrm{~km}$ & $30 \mathrm{~d}$ \\
\hline M0D13A3 & $\begin{array}{c}\text { Vegetation } \\
\text { index }\end{array}$ & $1 \mathrm{~km}$ & $30 \mathrm{~d}$ \\
\hline
\end{tabular}

To calculate daily vegetation index and 8-day synthesis vegetation index, surface albedo data of MODIS products are selected. The albedo products have 7 bands, and the calculate formula of Normalized Difference Vegetation Index (NDVI) and Enhanced Vegetation Index (EVI) as following [9]:

$$
N D V I=\frac{\rho_{2}-\rho_{1}}{\rho_{2}+\rho_{1}}
$$




$$
E V I=\frac{G\left(\rho_{2}-\rho_{1}\right)}{\rho_{2}+C_{1 \times} \rho_{1}-C_{2} \times \rho_{3}+L}
$$

Where, $\rho_{1} 、 \rho_{2} 、 \rho_{3}$ are the albedo of 1 th-band (620 670nm), 2nd-band $(841 \sim 876 \mathrm{~nm})$ and 3rd band (459 479nm) in MODIS sensor. In formula (1), G=2.5, C1=6, $\mathrm{C} 2=7.5, \mathrm{~L}=1$. With quality control files in MODIS products, pixels contaminated by cloud were excluded.

\section{B. Meteorological Data and Pre-processing}

There are 170 soil moisture observation stations, 52 national weather stations and 674 automatic weather stations in study area (Figure 1), including soil relative humidity data (\%) of $0-10 \mathrm{~cm}$ in June-September of 2006; diurnal precipitation $(\mathrm{mm})$ and temperature $\left({ }^{\circ} \mathrm{C}\right)$ in June-September of 2006 and time series data of monthly of precipitation and temperature in 1971-2000.

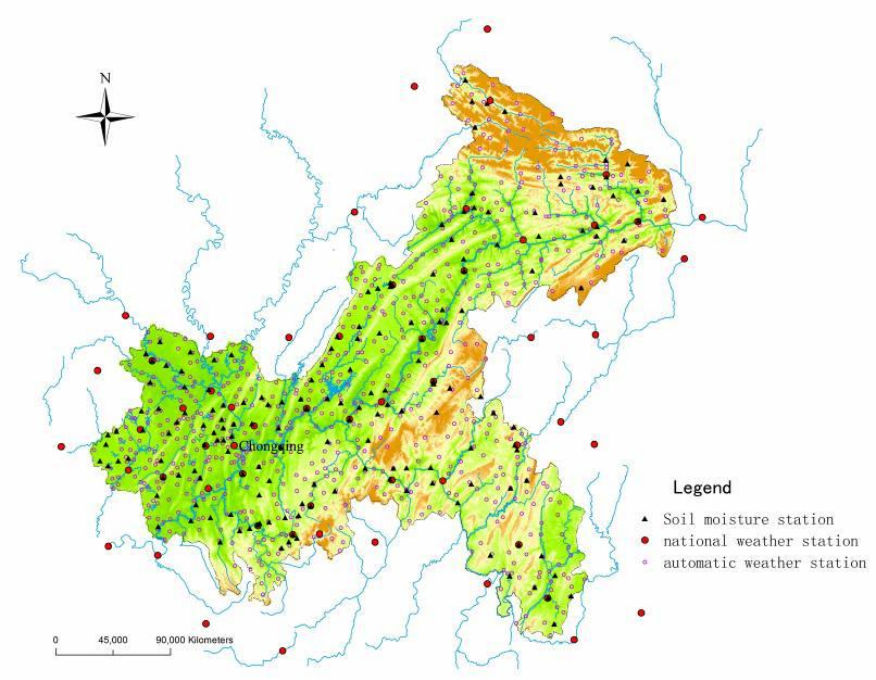

Figure 1. The distribution of meteorological stations and soil moisture stations in study area

\section{Vegetation Supply Water Index (VSWI)}

The principle of Vegetation Supply Water Index is as following: when water supply is normal, vegetation index gotten by remote sensor keep a range, and the crop crown temperature by remote sensor also keep some range; if drought emerges, the water supply of crop is insufficient. when crop growth is effected, and the vegetation index will decrease; on the other side, crop hasn't enough water for leaves evaporation because of water insufficient, and was forced to close part stomata which causes crop crown temperature rise $[10,11]$. National Satellite Meteorological Centre defined the vegetation supply water index as following:

$$
\mathrm{VSWIN}_{\mathrm{N}}=T_{s} / N D V I
$$

Because NDVI has some problems, so Enhanced Vegetation Index $(E V I)$ selected as vegetation parameter to calculate VSWI in this paper which is inherited and improved by NDVI.

$$
\mathrm{VSWI}_{E}=T_{s} / E V I
$$

Where, $T S$ is vegetation canopy temperature $(K)$. EVI is enhanced vegetation index. $V S W I_{N}$ and $V S W I_{E}$ are $V S W I$ calculated by NDVI and EVI respectively. VSWI is higher, means the crop canopy temperature is higher or vegetation is lower, which the drought is become severe.

\section{RESULTS AND ANALYSIS}

\section{A. VSWI and precipitation anomaly percentage}

Precipitation anomaly means to compare a period of precipitation with the average of historical period for many years, which reflect the deviate degree of precipitation from the normal range. Precipitation anomaly percentage is an important factor to assess drought, which generally defined 90d precipitation anomaly percentage $<20 \%$ of light drought, <$50 \%$ of severe drought. Chongqing is divided into five regions of northwest, southwestern, central, northeast, and southeast. Table II gives precipitation anomaly percentage statistics from June to August 2006 and June-September. From the table, northwest, southwest, central and northeastern districts were severe drought precipitation anomaly percentage of JuneAugust $<50 \%$ except southeast and northwestern is the most severe region with precipitation anomaly percentage reached $61.28 \%$. In mid-September, the drought has decreased, and the absolute value of precipitation anomaly percentage of JuneSeptember has reduced, but still in drought.

TABLE II. PRECIPITATION ANOMALY OF EACH DisTRICT IN CHONGQING, JUNE-SEP., 2006

\begin{tabular}{|c|c|c|}
\hline District & June-Aug. & June-Sep. \\
\hline Northwest & -61.28 & -50.05 \\
\hline Southwest & -56.61 & -48.35 \\
\hline central & -53.36 & -43.16 \\
\hline Northeast & -51.24 & -36.86 \\
\hline Southeast & -38.2 & -37.42 \\
\hline
\end{tabular}

5 typical stations of tongliang $\left(106.07^{\circ} \mathrm{E}, 29.82^{\circ} \mathrm{N}\right)$, Rongchang $\left(105.42^{\circ} \mathrm{E}, 29.60^{\circ} \mathrm{N}\right)$, Fuling $\left(107.42^{\circ} \mathrm{E}, 29.75^{\circ}\right.$ $\mathrm{N})$, Wanzhou $\left(108.40^{\circ} \mathrm{E}, 30.77^{\circ} \mathrm{N}\right)$, Qianjiang $\left(108.77^{\circ} \mathrm{E}\right.$, $29.53^{\circ} \mathrm{N}$ ) in the northwestern southwestern, central, Northeast, Southeast of Chongqing were selected to compare. Table 3 gives the comparison time between MODIS 8d synthetic data with the precipitation. From the figure 2, the changes of VSWI and precipitation are the consistent basically. The VSWI values are generally higher in no rain or dry periods, indicating that the drought aggravated; the VSWI values decreased significantly after precipitation, indicating drought mitigation. Inconsistent individual means the drought affected not only by precipitation, but also by the temperature, terrain conditions, irrigation and so on. 


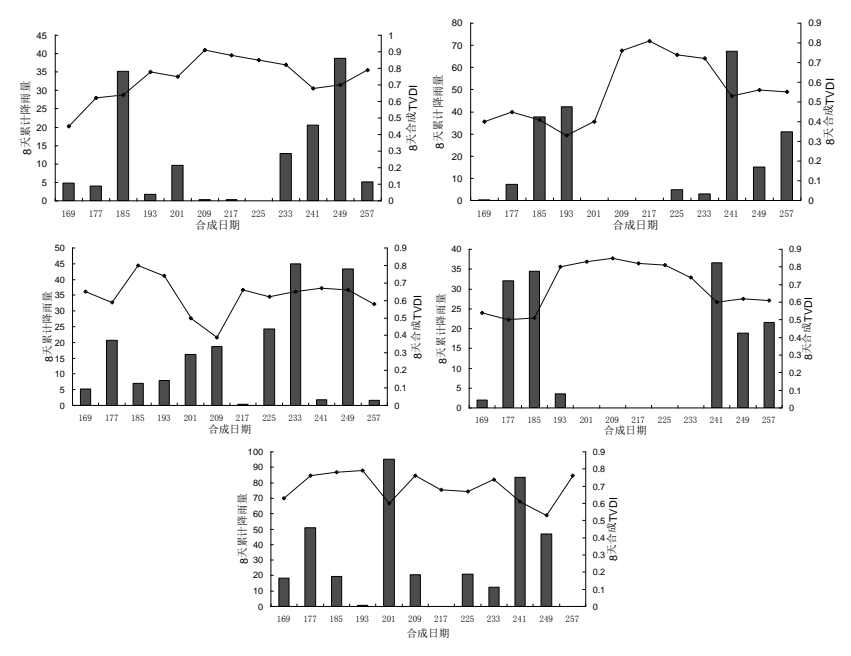

Figure 2. Architecture of landslide disaster forecast system

\section{B. VSWI and soil moisture}

To eliminate position errors, space analysis function in Arcgis9.3 was used. The average value of VSWI of 170 soil moisture observation sites were calculated by selecting $3 * 3$ window sizes respectively. Then As center were selected, which as the correspond index in soil moisture observation sites. Then through these values, correlation coefficient between $V S W I_{E}, V S W I_{N}$ and soil moisture data of $0-10 \mathrm{~cm}$ were calculated (table III).

TABLE III. CORRELATION COEFFICIENTS BETWEEN $V S W I_{E}, V S W I_{N}$ AND SOIL MOISTURE

\begin{tabular}{|c|c|c|}
\hline Day of year & $V S W I_{E}$ & $V S W I_{N}$ \\
\hline 169 & $-0.351^{* *}$ & $-0.412^{* *}$ \\
\hline 176 & $-0.185^{*}$ & $-0.176^{*}$ \\
\hline 195 & $-0.196^{*}$ & $-0.198^{*}$ \\
\hline 209 & $-0.222^{* *}$ & $-0.165^{*}$ \\
\hline 215 & $-0.227^{* *}$ & $-0.182^{*}$ \\
\hline 220 & $-0.267^{* *}$ & $-0.212^{*}$ \\
\hline 243 & $-0.416^{* *}$ & $-0.282^{* *}$ \\
\hline
\end{tabular}

** Means through 0.01significance examination, * Means through 0.05 significance examination.

From Table III, the correlation coefficients between soil moisture and VSWI reached significant level, which indicated that the VSWI can reflect the trend of soil moisture, and it was reasonable as drought evaluation indices. During 7 day's correlations between soil moisture and VSWI, the number of $\mathrm{p}<0.01$ between $V S W I_{E}$ and soil moisture reached 5 days, the number of $\mathrm{p}<0.05$ reached 2 days; while the corresponding number of correlations between $V S W I_{N}$ and soil moisture days were 2 days and 5 days. Therefore, $V S W I_{E}$ is more suitable than $V S W I_{N}$ for summer drought monitoring in Chongqing. The $V S W I$ referred later are calculated by the EVI and temperature data.

$8 \mathrm{~d}$ synthetic vegetation index and temperature MODIS data were used to calculate VSWI and soil moisture data similar to the number of days for correlation analysis, which also had a certain correlation (Table IV) and lower than single-day correlations. In 12 periods, there are 4 correlations was not significant. Considering a rapid change in real-time temperature data and diurnal moisture data, the accuracy and reliability of the $8 \mathrm{~d}$ synthetic data could be affected inevitably. But for Chongqing with clouds and complex climatic, it is practical to assess summer drought by $8 \mathrm{~d}$ synthetic data.

TABLE IV. Correlation CoefFicients BetweEn $V S W I_{E}$ AND SoIL MOISTURE

\begin{tabular}{|c|c|c|c|}
\hline Day of year & $V S W I_{E}$ & Day of year & $V S W I_{E}$ \\
\hline $169-176$ & $-0.227^{* *}$ & $177-184$ & $-0.165^{*}$ \\
\hline $185-192$ & -0.06 & $193-200$ & $-0.203^{* *}$ \\
\hline $201-208$ & -0.110 & $209-216$ & $-0.236^{* *}$ \\
\hline $217-224$ & $-0.260^{* *}$ & $225-232$ & $-0.214^{* *}$ \\
\hline $233-240$ & $-0.165^{* *}$ & $241-248$ & $-0.422^{* *}$ \\
\hline $249-256$ & -0.111 & $257-264$ & 0.060 \\
\hline
\end{tabular}

C. Spatial and temporal distribution of drought by $8 d$ synthetic VSWI in Chongqing

TABLE V. DROUGHT GRADING STANDARD OF VSWI

\begin{tabular}{|c|c|c|}
\hline Time & $\begin{array}{c}\text { Regression } \\
\text { equation }\end{array}$ & Grading standard \\
\hline $06 / 18-06 / 25$ & $\begin{array}{c}\mathrm{Y}=-0.7895 \mathrm{x}+ \\
114.47\end{array}$ & $\begin{array}{c}\text { Severe drought } \geqslant 95 ; 95>\text { mid } \\
\text { drought } \geqslant 80 ; 80>\text { light } \\
\text { drought } \geqslant 70 ; \text { suitable }<70\end{array}$ \\
\hline $06 / 26-07 / 03$ & $\begin{array}{c}\mathrm{Y}=-1.5354 \mathrm{x}+ \\
189.21\end{array}$ & $\begin{array}{c}\text { Severe drought } \geqslant 97 ; 97>\text { mid } \\
\text { drought } \geqslant 91 ; 91>\text { light } \\
\text { drought } \geqslant 84 ; \text { suitable }<84\end{array}$ \\
\hline $07 / 04-07 / 11$ & - & - \\
\hline $07 / 12-07 / 19$ & $\mathrm{Y}=-0.8435 \mathrm{x}+$ & $\begin{array}{c}\text { Severe drought } \geqslant 95 ; 95>\text { mid } \\
\text { drought } \geqslant 80 ; 80>\text { light } \\
\text { drought } \geqslant 72 ; \text { suitable }<72\end{array}$ \\
\hline $07 / 20-07 / 27$ & - & - \\
\hline $07 / 28-08 / 04$ & $\begin{array}{c}\mathrm{Y}=-0.7558 \mathrm{x}+ \\
109.71\end{array}$ & $\begin{array}{c}\text { Severe drought } \geqslant 93 ; 93>\text { mid } \\
\text { drought } \geqslant 77 ; 77>\text { light } \\
\text { drought } \geqslant 67 ; \text { suitable }<67\end{array}$ \\
\hline $08 / 05-08 / 12$ & $\begin{array}{c}\mathrm{Y}=-0.4514 \mathrm{x}+ \\
83.551\end{array}$ & $\begin{array}{c}\text { Severe drought } \geqslant 98 ; 98>\text { mid } \\
\text { drought } \geqslant 70 ; 70>\text { light } \\
\text { drought } \geqslant 55 ; \text { suitable }<55\end{array}$ \\
\hline $08 / 13-08 / 20$ & $\begin{array}{c}\mathrm{Y}=-0.4286 \mathrm{x} \\
+82.143\end{array}$ & $\begin{array}{c}\text { Severe drought } \geqslant 100 ; 100>\text { mid } \\
\text { drought } \geqslant 70 ; 70>\text { light } \\
\text { drought } \geqslant 55 ; \text { suitable }<55\end{array}$ \\
\hline
\end{tabular}




\begin{tabular}{|c|c|c|}
\hline $08 / 21-08 / 28$ & $\begin{array}{c}\mathrm{Y}=-0.4764 \mathrm{x} \\
+86.046\end{array}$ & $\begin{array}{c}\text { Severe drought } \geqslant 98 ; 98>\text { mid } \\
\text { drought } \geqslant 72 ; 72>\text { light } \\
\text { drought } \geqslant 57 ; \text { suitable }<57\end{array}$ \\
\hline $08 / 29-09 / 05$ & $\begin{array}{r}\mathrm{Y}=-0.3551 \mathrm{x} \\
+77.577\end{array}$ & $\begin{array}{c}\text { Severe drought } \geqslant 108 ; 108>\text { mid } \\
\text { drought } \geqslant 70 ; 70>\text { light } \\
\text { drought } \geqslant 55 ; \text { suitable }<55\end{array}$ \\
\hline $09 / 06-09 / 13$ & - & - \\
\hline $09 / 14-09 / 21$ & - & - \\
\hline
\end{tabular}

TABLE VI. REMOTE SENSING DATA STATISTICS IN 2006 CHONGQING SUMMER DROUGHT

\begin{tabular}{|c|c|c|c|c|}
\hline Time & suitable & $\begin{array}{c}\text { light } \\
\text { drought }\end{array}$ & $\begin{array}{c}\text { mid } \\
\text { drought }\end{array}$ & $\begin{array}{c}\text { Severe } \\
\text { drought }\end{array}$ \\
\hline $06 / 18-06 / 25$ & 73.89 & 16.60 & 6.24 & 3.27 \\
\hline $06 / 26-07 / 03$ & 88.67 & 5.81 & 3.62 & 1.90 \\
\hline $07 / 04-07 / 11$ & - & - & - & - \\
\hline $07 / 12-07 / 19$ & 86.84 & 6.43 & 3.85 & 2.88 \\
\hline $07 / 20-07 / 27$ & - & - & - & - \\
\hline $07 / 28-08 / 04$ & 51.84 & 19.91 & 19.68 & 8.57 \\
\hline $08 / 05-08 / 12$ & 25.13 & 27.13 & 33.58 & 14.16 \\
\hline $08 / 13-08 / 20$ & 22.55 & 30.80 & 27.22 & 19.44 \\
\hline $08 / 21-08 / 28$ & 18.17 & 28.41 & 31.55 & 21.86 \\
\hline $08 / 29-09 / 05$ & 10.27 & 18.05 & 35.25 & 36.44 \\
\hline $09 / 06-09 / 13$ & - & - & - & - \\
\hline $09 / 14-09 / 21$ & - & - & - & - \\
\hline
\end{tabular}

- Means the equation is no correlation.

A drought grading standard has been developed which soil relative humidity $<40 \%$ means severe drought, $40 \%$ to $50 \%$ means mid drought, $50 \%$ to $60 \%$ means light drought, $60 \%$ to $90 \%$ means suitable. Therefore, this paper transformed it into 4 levels of $8 \mathrm{~d}$ synthetic VSWI by the regression equation between soil moisture and VSWI. The pixel number and the percentage of each level was been calculated according to the classification. If there is no correlation, then the equation cannot be regressed. The statistical results are shown in Table $\mathrm{V}$ and Table VI.

The whole process of 2006 severe drought changed from occurred - increased - relieved - increased again - complete remission in Chongqing. June 18 - June 25, 73.89\% of total area in suitable condition, $16.60 \%$ in mild drought, $9.51 \%$ in dry drought located mainly in northeast. June 16-July 19, the most areas are in suitable condition. July 28-August 4, 51.84\% is suitable, $19.91 \%$ in light dry drought, $19.68 \%$ in mid drought, $8.57 \%$ in dry drought, mainly in the northwestern, northeastern and southeastern. August 5 - August 12, only $25.13 \%$ is suitable, $27.13 \%$ in light drought, $33.58 \%$ in mid drought, $14.16 \%$ in severe drought. August 13 - August 20, the entire western area were in severe drought, the drought in central become more serious, only $22.55 \%$ is suitable, $30.80 \%$ in light drought, $27.22 \%$ in mid drought, $19.44 \%$ in severe drought. August 21 - August 28, only $18.17 \%$ is suitable, $28.41 \%$ in light drought, $31.55 \%$ in the mid drought, $21.86 \%$ in severe drought. August 29 - September 5, in addition to the northeast and southeast was still in suitable, other area have different drought grads, only $10.27 \%$ of the city area is suitable, $18.05 \%$ in light drought, $35.25 \%$ in the mid drought, $36.44 \%$ in severe drought.

\section{CONCLUSION AND DISCUSSION}

MODIS product data of single-day and $8 \mathrm{~d}$ synthesis from June to September in 2006 to construct vegetation supply water index (VSWI) for Chongqing summer drought, and validated results by soil moisture. The results showed that: (1) $V S W I_{E}$ built by $E V I$ was more suitable for monitoring summer drought in Chongqing than $V S W I_{N}$ built by $N D V I$, and VSWI built by single-day MODIS data has better correlation than VSWI built by 8-day synthetic MODIS data; (2) VSWI had a certain negative correlation with precipitation; (3) VSWI could effectively reflect the spatial and temporal differences in soil moisture, and it was an effective mean to assess summer drought.

There are still some shortcomings in this study, mainly in: (1) there is deviation to verify the accuracy of VSWI by soil moisture; (2) Although the quality control has been carried out (cloud detection, etc.), but there are still poor quality pixel which affected the accuracy of validation results; (3) other vegetation index such as leaf area index ( $L A I)$ should be used in summer drought assessment.

\section{REFERENCES}

[1] Obasi G O. WHO's Role in the international decade for natural disaster reduction[J].Bulletin of the American Meteorological Society, 1994, 75:1661-1665.

[2] Tian Guoliang, Thermal Remote Sensing, Publishing House of Electronics Industry, Beijing, 2005.

[3] Price J.C.Using spatial context in satellite data to infer regional scale evapotranspiration[J].IEEE Transactions on Geosciences and Remote Sensing, 1990,(28):940-948.

[4] Shi Jiancheng, L. J., Lixin Zhang. A Parameterized Multifrequency-polarization Surface Emission Model[J].IEEE Transactions on Geosciences and Remote Sensing,2005,43:2831-2841.

[5] Han Lijuan, Wang Pengxin, Wang Jindi,et al. Study of feature space of Vegetation Index - LST. Chinese Science Series D Earth Sciences 2005,35(4):371-377.

[6] Wang Pengxin,Sun Wei.COMPARISON STUTY ON NDVI AND LST BASED DROUGHT MONITORING APPROACHES.Journal of Beijing Normal University(Natural Science).2007,43(3):319-323.

[7] Qi Shuhua, Wang Changyao,Niu Zheng. Evaluating Soil Moisture Status in China Using the Temperature/Vegetation Dryness Index $(T V D I)$. JOURNAL OF REMOTE SENSING.2003,7(5):420-427

[8] Justice C O.An overview of MODIS land data processing and product status [J].Remote Sensing of Environment, 2002, 83:3-15.

[9] A.Huete. K. D. Overview of the radiometric and biophysical performance of the MODIS vegetation indices[J].Remote Sensing of Environment,2002,83(1):195-213.

[10] .Zhang Shuyu,Li Dengke,Li Xingmin,et al. Application of MODIS Data on Drought Monitoring in Shanxi Province for Spring of 2005. Chinese Journal of Agrometeorology,2006,27(3):204-209.

[11] Li Xingmin, Yang Xingguo,Wang zhao,et al. Method of Drought Monitor by Remote Sensing in Four Provines of Northwest China: Erads Software as an Example. ARD METEOROLOGY, 2007,25(1):83-87. 